\title{
Bruno Tolentino e a poética classicizante: o caso de A balada do cárcere
}

Érico Nogueira

Universidade Federal de São Paulo

\section{Classicismo pós-cabralino}

7 matéria de poesia e poética, os anos noventa do século 1 XX talvez possam descrever-se, no Brasil, como a década de João Cabral de Melo Neto, ou, mais exatamente, como o período culminante de sua canonização, iniciada em 1942 com a publicação de um então promissor volume de estreia ${ }^{1}$. Príncipe dos poetas brasileiros desde a morte de Drummond em 1987, e ganhador, em 1990, do prestigiosíssimo Prêmio Camões, Cabral teve a obra completa ${ }^{2}$ lançada pela primeira vez em 1994, e uma segunda e atualizada edição em dois volumes de sua poesia completa ${ }^{3}$ em 1997, publicações essas que, secundadas pela aclamação de poetas, críticos e professores universitários do porte de Haroldo de Campos ${ }^{4}$, João Alexandre Barbosa $^{5}$ e Antonio Carlos Secchin ${ }^{6}$, entre tantos outros, lhe

\footnotetext{
${ }^{1}$ Cf. CANDIDO, 2002, p. 135-142.

${ }^{2}$ Cf. Melo Neto, 1994.

${ }^{3}$ Cf. Melo Neto, 1997.

${ }^{4}$ Cf. CAMPOS, 2000.

${ }^{5}$ Cf. BARBOSA, 2001.

${ }^{6}$ Cf. SeCCHIN, 1999.
} 
valeram a ele, ou antes a seus princípios compositivos, uma preeminência e autoridade que beiravam o vigor de lei. Num clima poético como esse, dominado por palavras de ordem como "antilirismo", "concretude", "objetividade" e "concentração", a poesia filosófica e classicamente lírica de Tolentino soou como música nova aos ouvidos mais atentos ${ }^{7}$.

Com efeito, ainda que seu primeiro e premiado livro, Anulação E Outros Reparos ${ }^{8}$, haja aparecido em 1963, os trinta longos anos que permaneceu na Europa, durante os quais não publicou uma só linha no idioma de Camões, permitem que se considere As horas de Katharina, lançado em 1994 e galardoado com o Jabuti em 1995, como sua real e verdadeira estreia. Tanto assim é que já em 1998 vinha à luz a edição definitiva, revista e aumentada, de Anulação, que o próprio autor chamava de "o mais ralo" de seus livros ${ }^{9}$. Seja como for, a dupla circunstância de a última recolha de Cabral constante apenas de poemas inéditos ${ }^{10}$ datar de 1990, e de Tolentino haver retornado - ou surgido - ao cenário poético nacional em 1994, é razão bastante para afirmar, dada a repercussão desse retorno ou surgimento ${ }^{11}$,

7 Cf. JABOR, 1994.

${ }^{8}$ Cf. Tolentino, 1963. Estelivrovenceu o Prêmio Revelação de Autor em 1960. ${ }^{9}$ Cf. Tolentino, 1998, p. 276: “Com a pachorra da lesma e a diligência da toupeira, esperei que toda uma vida se pusesse por trás de cada um de meus livros para dá-los a público - quanto mais para consentir na reimpressão do mais ralo deles!".

${ }^{10}$ Cf. Melo Neto, 1990.

${ }^{11}$ Com a exceção de Os deuses de hoje (1995) e Os sapos de ontem (1995) - este último um livro de circunstância escrito em resposta a um problema real -, todos os livros que Bruno Tolentino publicou após sua volta ao Brasil foram premiados: As horas de Katharina (1994) venceu o Prêmio Jabuti em 1995; A balada do cárcere (1996), o Cruz e Souza e o Abgar Renault, respectivamente em 1996 e em 1997; O mundo como ideia venceu outro Jabuti e o Senador José Ermírio de Moraes em 2003; e A imitação do amanhecer (2006), um inédito Jabuti 
que Tolentino encarna e entroniza uma inequívoca tendência classicizante na poesia brasileira pós-cabralina, tendência essa que, de resto, só tem recrudescido desde então ${ }^{12}$.

Ainda assim, passados mais de vinte anos de sua reestreia no mercado editorial brasileiro - e sete desde sua morte -, a escassez de estudos críticos e trabalhos acadêmicos sobre a poesia de Bruno Tolentino não pode senão espantar. Comentando esse fato, Felipe Simas Rabello assinala que ${ }^{13}$ :

Considerado este panorama, o maior norte - tanto para esta dissertação como para os demais estudos antigos e vindouros - foi e continua sendo o legado crítico que Bruno Tolentino nos deixou acerca de sua própria obra, principalmente o ensaio "A gênese do livro: um prólogo", encontrado no início de $O$ mundo como ideia. Certamente há outros escritos do poeta relevantes a pontos específicos, como o epílogo da edição definitiva de Anulação $\mathcal{E}$ outros reparos, intitulado "Duas reflexões do autor à margem da edição definitiva", ou o ensaio "A farsa como história", prólogo de Os sapos de

póstumo em 2007. Esses prêmios - que, se não são a história toda, ao menos são parte da história - dão sem dúvida nenhuma alguma ideia da repercussão que aludimos acima. Cf. Tolentino, 1996b.

${ }^{12}$ Sem pretender fazer lista exaustiva - e deliberadamente excluindo dela os já mencionados livros de Bruno Tolentino-, é possível detectar expedientes classicizantes em obras premiadas como Trovar claro (1997) e Macau (2003), de Paulo Henriques Britto; Invenção do mar (1998), de Gerardo Mello Mourão; Poesia reunida (2003), de Alexei Bueno; O outro lado (2007), de Ivan Junqueira; O livro de Scardanelli (2008), de Érico Nogueira; e em muitas outras. De maneira que, no que toca ao público reconhecimento outorgado por prêmios e galardões, os poetas de tendência classicizante não se encontram, no Brasil de hoje, em situação inferior aos demais.

${ }^{13}$ Cf. Simas Rabello, 2010. Trata-se de trabalho pioneiro, sendo, como é, o primeiro estudo acadêmico voltado à poesia de Tolentino, no Brasil ou no estrangeiro. 
ontem, cuja veia polêmica não ofusca a importância de suas ponderações para a própria opção estética que escolheu como guia, e até mesmo para seu papel de herdeiro de uma geração e, consequentemente, de antípoda de outra. No entanto, esses escritos não possuem nem a generalidade nem o caráter hermenêutico fundamental apresentado pelo prefácio de $O$ mundo como ideia. Em suma, se há um trabalho crítico imprescindível para a compreensão da obra de Bruno Tolentino, este trabalho foi-nos entregue pelo próprio autor e deve ser considerado como um ponto de partida para qualquer análise de sua obra.

Se, pois, estribados no longo prefácio de $O$ mundo como ideia, pudermos definir numa única palavra a poética que defende, diremos que se trata de empresa classicizante - quando menos, porque, a despeito de tudo o que evidentemente distingue Bruno Tolentino dos poetas árcades (protótipos da tendência classicizante entre nós), a circunstância de pretender definir a) a natureza e a finalidade da poesia, b) a forma do poema e c) o mister do poeta, e de atribuir valor paradigmático às suas definições, insere o seu programa poético em tradição que, de Horácio a Boileau e Cândido Lusitano, vem-se chamando clássica, neoclássica ou qualquer outra denominação equivalente ${ }^{14}$. Com efeito, sendo esses três autores, como são,modelos autorizados do classicismo literário, todo programa que se articule em torno dos três eixos ou partes

${ }^{14} \mathrm{O}$ adjetivo classicus, em latim, cujo sentido original é "de primeira classe ou grandeza", foi aplicado por Aulo Gélio (125 d. C. - 180 d. C.) para descrever os autores modelares, que deviam ser imitados e glosados por quem quer que aspirasse à correção do idioma. Desse modo, autor ou poesia clássicos são simplesmente os de primeira classe ou ordem, que se erigem em modelo ou norma para os demais. Todas as poéticas classicizantes, a de Tolentino inclusive, apresentam, em alguma medida, essa pretensão normativa ou modelar. Cf. CurTius, 1993, p. 253-256. 
principais em que eles dividem a poética - a saber: a arte, a obra e o artífice ${ }^{15}$-, e que, ao fazê-lo, busque princípios ou regras gerais, válidas para todos os gêneros da poesia, participa, em grau maior ou menor, do mesmo classicismo de que eles são modelos. Vejamos como e por que é precisamente este o caso de Tolentino.

Desde a Poética de Aristóteles, passando pelo célebre ut pictura poesis horaciano, a comparação entre poesia e pintura é um lugar-comum obrigatório nas poéticas ditas clássicas ou neoclássicas ${ }^{16}$. Não seria Tolentino a fugir a essa regra: de fato, toda a longa reflexão teórica que precede os poemas de $O$ mundo como ideia não é outra coisa que a reproposição, em termos bastante originais, da relação entre o sensível e o inteligível, o concreto e o abstrato, o temporal e o intemporal, estudada por Yves Bonnefoy nas artes pictóricas e na poesia ${ }^{17}$. Assim sendo, compreende-se melhor a descrição do cerne e escopo desta última que Tolentino nos oferece no final do mencionado prefácio ${ }^{18}$ :

Assim como na genuína música que se faz com ideias, no poema clara e organicamente enunciado, assim nas telas e afrescos e vitrais e mosaicos em que a grande arte confronta a enfermidade do olhar, adverte-se a imanência do eterno no sensível: em qualquer desses difíceis, frágeis triunfos, brilha perfurando a bruma o mundo reconciliado para além das loucas teosofias da Ideia.

Ora, partindo da célebre definição de Ricardo Reis ${ }^{19}$, e desde logo equiparando o poema bem logrado com o mosaico,

\footnotetext{
${ }^{15}$ Cf. LAusberg, 2008, p. 552-554.

${ }^{16}$ Cf. Simas Rabello, 2014.

17 Cf. Bonnefoy, 1992. Cf. também, para uma sucinta e exata apresentação da poética de Bonnefoy, SIMPSON, 2006, p. 19-32.

${ }^{18}$ Tolentino, 2002, p. 84.

${ }^{19}$ Cf. PessOA, 1974, p. 142: “Eu, porém, antes diria que a poesia é uma música que se faz com ideias, e por isso com palavras".
} 
o vitral, o afresco e a tela, Tolentino a expande e especifica de tal modo que, ao fim e ao cabo, produz nova definição: genuína poesia é aquela música (de palavras) que, primeiro, a par e par das artes pictóricas, sabe-se abstrata sem ser idealista, e que, segundo, aberta à transcendência mas atenta ao imediato, reconcilia o inteligível com o sensível sem pretender substituir nenhum dos dois. Música de ideias, portanto, não da Ideia. Constructo mental ciente da própria precariedade, não emplasto Brás Cubas nem pedra filosofal.

Na condição de constructo, pois, o poema, instância particular que a definição geral de poesia necessariamente assume ao manifestar-se, possui característicos elocutórios mais ou menos apropriados para a hercúlea tarefa de reunir o eterno e o efêmero, o que evidentemente leva o poeta a procurar o melhor meio de cumpri-la: forma fixa, verso livre ou suportes materiais de vanguarda? A resposta de Bruno é reveladora ${ }^{20}$ :

Quaisquer que fossem as inevitáveis questões técnicoexpressivas a um dado momento, a forma ou era a tradução natural e concisa, perene e atual, de valores igualmente temporais e - como não? - espirituais, ou era muda, morta, informe.

De uma tal perspectiva, portanto, a oposição entre tradicionalismo e vanguarda, classicismo e romantismo, antigos e modernos é uma falsa oposição, porque ou bem o poeta, usando a forma que lhe aprouver, consegue fundir o temporal e o espiritual no seu poema, ou bem o não consegue - e ponto final. Logo, a preferência de Tolentino pelas formas tradicionais é menos "um desejo de contrarreforma no âmbito da modernidade", como a ela se referiu Marcos Siscar em artigo

${ }^{20}$ TolentinO, 2002, p. 83. 
recente $^{21}$, do que a maneira absolutamente pessoal, e nesse sentido intransferível, que o poeta encontrou para desempenhar o melhor que pudesse o que julga ser o seu mister. Se foi bemsucedido ou não (e a nós nos parece que foi), aí é outra história.

Enfim, ao conceber a poesia como música de ideias, o poema como forma plural, e o ofício do poeta como reconciliação do fugaz e do transcendente - e, ademais, pretender que tal concepção tenha validade mais ou menos geral, para além de vicissitudes e particularismos -, Tolentino não só se insere na antiga e venerável tradição clássica como também, no interior dessa tradição, dá continuidade à poesia do pensamento tão exemplarmente representada por Luís de Camões, Antero de Quental, Fernando Pessoa e Carlos Drummond de Andrade, em português ${ }^{22}$. Posto isso, e sabendo que tal programa foi duro questionamento da poética dominante ao longo da década de 1990, passemos, finalmente, à consideração de A balada do cárcere.

\section{Poesia e Conhecimento de Si}

De um ponto de vista histórico-biográfico, a publicação de A balada do cárcere em 1996 pode ser interpretada como a mais consistente resposta do autor a uma querela iniciada dois anos antes nas páginas de $O$ Estado de São Paulo, e à qual o professor John Milton, em artigo inteligente e imparcial, muito corretamente chamou "a guerra das traduções" 23 . Para além de pura (e acerba) altercação sobre tradução literária, contudo, a querela entre Augusto de Campos e Bruno Tolentino foi

${ }^{21}$ Cf. Siscar, 2013, p. 110.

${ }^{22}$ Tal enumeração não é nem pretende ser exaustiva, e inclui nomes como o brasileiro Alberto da Cunha Melo e o português António Franco Alexandre, entre outros.

${ }^{23}$ Cf. Milton, 1996, p. 13-26. 
também, e principalmente, um confronto entre mundividências e poéticas opostas, e ofereceu a este último, que se encontrava em situação bem distinta da do primeiro no tocante ao lugar, influência e reconhecimento público de sua obra, a dupla ocasião de fazer-se conhecer e, ao mesmo tempo, atacando uma das pedras-de-toque da poética de Campos, como era e é sua reconhecida competência tradutória, questionar-lhe a própria centralidade no ensino acadêmico e no debate público sobre poesia no Brasil ${ }^{24}$.

Nada obstante, A balada do cárcere não é um libelo contra a teoria e a prática tradutórias dos poetas concretos em geral, e de Augusto em particular - senão, isto sim, um libreto para ser lido sem nenhum outro acompanhamento que a simples música das palavras, e cujo viés polêmico põe em xeque as premissas e conclusões teórico-críticas defendidas por Campos

${ }^{24}$ Cf.Milton, 1996, p. 21: "Enquanto a linguagem de Augusto de Campos [durante a querela] é a de alguém que está 'no centro' e que quer ficar lá, a linguagem de Bruno Tolentino é de alguém que quer entrar, que quer tomar o lugar que Augusto de Campos atualmente ocupa. Uma grande ironia é que Augusto de Campos frequentemente usa o termo 'vanguardista' para se descrever, enquanto defende o poder que conquistou. Mas é impossível para um poeta que já tem um certo sucesso ficar sempre na vanguarda". Ainda que se note, talvez, uma pequena queda de prestígio da poética de Campos - que hoje divide a primazia universitária com uma espécie de multiculturalismo tupiniquim -, e uma pequena elevação da de Tolentino - que apenas começa a ser objeto de estudos acadêmicos -, a situação que John Milton descreve em 1996 é basicamente a mesma em 2014. Por isso mesmo, é justo mencionar aqui a pesquisa que Juliana Perez tem desenvolvido sobre a poesia de Bruno Tolentino. Professora de literatura alemã na Universidade de São Paulo, o trabalho de Perez tem ajudado bastante a preencher essa lacuna bibliográfica. Para maiores informações sobre os artigos já publicados, vide bibliografia final. 
desde o pioneiro O balanço da bossa, publicado em 1968. Em poucas palavras, ao aproximar especialmente as canções de Caetano Veloso e Gilberto Gil da arte de vanguarda, e considerar algumas de suas letras como verdadeiros poemas, Augusto de Campos criava um filão em si mesmo rico e prenhe de sugestões inovadoras, decerto, mas que, explorado à exaustão pelo establishment acadêmico e jornalístico ${ }^{25}$, acabaria por ingenuamente equiparar poesia com letra de canção - realidades essas que, embora passíveis de se comparar, em geral não têm nem podem ter o mesmo valor artístico de um ponto de vista exclusivamente retórico ou literário.

Em vez de se concentrar no aspecto puramente elocutório, porém, logo no início de seu prefácio à Balada Tolentino distingue poesia e letra, entre outros característicos que tais, pela verticalidade que julga constitutiva daquela, em contraste com a predominante horizontalidade desta ${ }^{26}$. Distinção indubitavelmente clássica que encarece a relativa precedência do assunto sobre o estilo ${ }^{27}$ - porquanto é a matéria em princípio mais elevada e profunda da poesia a reclamar uma forma que, lançando mão de recursos linguísticos mais amplos e complexos que os da letra de canção, é por isso mesmo mais adequada à maior complexidade e amplitude do que o poema enuncia -, ela requer que se especifique, de uma maneira ou de outra, que matéria ou assunto tão altos e arcanos são esses, afinal. $O$ poeta não se faz de rogado ${ }^{28}$ :

${ }^{25} \mathrm{Cf}$., a propósito, sobre a transformação do projeto concretista, de vanguarda em status quo,Milton, 1996, p. 20.

${ }^{26}$ Cf. Tolentino, 1996, p. 9: “E, malgrado a grandiosidade dos negro spirituals, por exemplo, mantenho que só a poesia, a linguagem profunda de uma raça, tem a amplitude de meios capazes de dar à complexidade da condição humana aquela dimensão de verticalidade correspondente às grandes perplexidades da alma".

${ }^{27}$ Cf. Lausberg, 2008, p. 507-511.

${ }^{28}$ Tolentino, 1996, p. 11. 
... as áreas de ambiguidade inseparáveis da busca de autoconhecimento, o chiaroscuro da consciência, aquelas shades of meaning do eterno paradoxo humano. A tudo isso corresponde em seus mais puros momentos apenas a arte da poesia [...].

Dessa maneira, o tema de $A$ balada do cárcere não é outro senão a passagem da inconsciência para a consciência, ou da ignorância para o conhecimento de si, representada como progressiva aquisição de uma linguagem capaz de articular tão exatamente quanto possível isto mesmo (o eu profundo) que se passou a conhecer - ou, numa palavra, o livro é um drama de consciência a par e par de um drama de linguagem, e vice-versa. Que isto não seja assunto para letra de canção - pelo simples e patente motivo de, nela e por ela, não poder ser desenvolvido como convém - parece uma obviedade.

Constante de quarenta e três poemas irregularmente divididos em três seções, e com predominância do decassílabo e do heptassílabo sobre outros metros menos frequentes, $A$ balada do cárcere é, portanto, o relato ficcional do narrador sobre sua experiência (real) na cadeia britânica, centrado na figura de um misterioso condenado à prisão perpétua a que chama o Numeropata, ou, etimologicamente, "o que sofre do número". Ora, se sofrer do número, ou do mal do número, é exatamente o que caracteriza o artista e poeta idealista que, fazendo música da Ideia, não de ideias, pretende que sua obra reconstrua e ao fim e ao cabo substitua o mundo-como-tal ${ }^{29}$, então o Numeropata, quer haja ou não existido uma pessoa de carne e osso que lhe serviu de modelo, é antes de tudo e por tudo um alter ego do narrador, cuja função eminentemente didática, na economia do

${ }^{29}$ Cf. TolEnTINO, 2002, p. 25: “... mais claramente que em todas as artes, na arte do visível o mundo-como-ideia apodera-se do real tratando de substituí-lo pela ancestral magia do número [...]". 
livro, é a de alegoria e exemplo do artista em prisão perpétua, que insiste em trocar o real pelo ideal, mas que alcança a liberdade possível quando toma consciência de si e de suas forças, as quais reconhece incapazes de criar artefato nenhum que faça as vezes da vida. Entre a Ideia e o mundo, portanto, o Numeropata felizmente escolhe a segunda opção.

Não por acaso, conforme se lê em entrevista publicada como apêndice à primeira edição da $\mathrm{Balada}^{30}$, a transformação do Numeropata é muito semelhante à de Tolentino em pessoa, que entrou na cadeia como esteta, e saiu poeta consumado. Sabendo das vicissitudes reais que o afligiram ${ }^{31}$, fica difícil não ler $A$ balada do cárcere como o testemunho (ficcional) de uma vivência concreta, no qual o depoente nos conta via personagens como a conquista da verdadeira poesia redunda em autoconhecimento, ou, inversamente, como o conhecimento de si leva à aquisição da verdadeira linguagem: desde que língua e consciência andem juntas, a ordem pouco importa.

Dessa maneira, esperamos haver mostrado que a poética teórica e impessoalmente formulada no prefácio de $O$ mundo como ideia ganha, no entrecho de $A$ balada do cárcere, tratamento dramático e pessoal. Também este é traço classicizante: com efeito, ao vincular a poesia ao conhecimento de si, e compor um drama lírico sobre a aquisição de ambos, Tolentino não faz outra

${ }^{30}$ Cf. Tolentino, 1996, p. 126: "Foi uma coisa fabulosa, tenho saudades daquele tempo [da prisão] que enriqueceu minha vida pessoal e revolucionou minha percepção das artes da linguagem. Prenderam um esteta e soltaram um poeta!".

${ }^{31}$ Muito sucintamente, saiba-se que Tolentino, que então vivia na Inglaterra, foi lá condenado a onze anos de prisão por tráfico internacional de entorpecentes, sentença de que chegou a cumprir a metade, de setembro de 1987 ao início de 1993, ano em que foi deportado para o Brasil. 
coisa do que seguir um preceito de Horácio - um clássico entre os clássicos -, segundo quem a sabedoria é o princípio da poesia ${ }^{32}$.

Finalmente, a julgar pelos prêmios que recebeu e pelas polêmicas em que se engajou, é possível dizer que Bruno Tolentino criou as condições para que uma poesia de cunho classicizante, mais especulativa e menos materialista, voltasse a ser lida e apreciada na academia e nos grandes meios de comunicação do Brasil pós-cabralino. De fato, ousando dar vida nova à mais genuína e clássica tradição do idioma caracterizada, desde Luís de Camões, por linguagem que funde pensamento e emoção e eleva as contradições do sujeito às raias do transcendente -, Tolentino recolocou a tendência classicizante na ordem do dia, e, desse modo, ajudou a construir o cenário da poesia brasileira atual. Goste-se dele ou não, é feito que merece ser reconhecido.

${ }^{32}$ Cf. HoRÁCIO, 1984, v. 309-311: Scribendi recte sapere est et principium et fons. / Rem tibi Socraticae poterunt ostendere chartae, / uerbaque prouisam rem non inuita sequentur. "Ser sabedor é o princípio e a fonte do bem escrever. Os escritos socráticos já te deram ideias e agora as palavras seguirão, sem esforço, o assunto imaginado." A menção a Sócrates vem bastante a calhar, e é indício eloquente de que a sabedoria assinalada por Horácio é antes de tudo e sobretudo o socrático conhecimento de si. 


\section{Referências bibliográficas}

Alexandre, António Franco. Aracne. Lisboa: Assírio \& Alvim, 2004.

Barbosa, João Alexandre.João Cabral de Melo Neto. Coleção Folha Explica. São Paulo: Publifolha, 2001.

Britto, Paulo Henriques. Macau. São Paulo: Companhia das Letras, 2003.

. Trovar claro. São Paulo: Companhia das Letras, 1997.

Bueno, Alexei. Poesia reunida. Rio de Janeiro: Nova Fronteira, 2003.

Bonnefoy, Yves. L'improbable et autres essais. Paris: Gallimard, 1992.

CAMÕES, Luís Vaz de.Obra completa. Rio de Janeiro: Nova Aguilar, 2003.

Campos, Haroldo de. Os 'Poetas Concretos' e João Cabral de Melo Neto. Um Testemunho. Revista Colóquio / Letras, n 157-158, pp. 27-32, julho de 2000.

CAndido,Antonio. "Notas de Crítica Literária - Poesia ao Norte". Textos de intervenção. Seleção, apresentação e notas de Vinícius Dantas. São Paulo: Duas Cidades / Editora 34, 2002.

Cunha Melo, Alberto da. Dois Caminhos e Uma Oração. São Paulo: A Girafa, 2003.

CuRTIUs, Ernst Robert.Europäische Literatur und Lateinisches Mittelalter. 11. Auflage. Tübingen / Basel: Francke Verlag, 1993.

Drummond de Andrade, Carlos. Poesia completa. Rio de Janeiro: Nova Aguilar, 2002.

Horácio. Arte poética. Introdução, tradução e comentário de R. M. Rosado Fernandes. $4^{\mathrm{a}}$ edição. Mem Martins: Editorial Inquérito, 1984.

JABOR, Arnaldo. “Tolentino traz de volta a peste clássica". Folha de São Paulo, Caderno "Ilustrada", 19 de julho de 1994.

JunQUeIRA, Ivan. O outro lado. São Paulo: Record, 2007.

LAUSBERG, Heinrich. Handbuch der literarischen rhetorik. 4. Auflage. Stuttgart: Franz Steiner, 2008. 
Melo Neto, João Cabral de. Serial e antes. A educação pela pedra e depois. 2 Volumes. Rio de Janeiro: Nova Fronteira, 1997. . Obra completa. Rio de Janeiro: Nova Aguilar, 1994. . Sevilha andando. Rio de Janeiro: Nova Fronteira, 1990.

MitTon, John. "Augusto de Campos e Bruno Tolentino: a guerra das traduções". Cadernos de tradução, vol. 1, n 1, 1996, pp. 13-26.

Mourão, Gerardo Mello. Invenção do mar. SãoPaulo: Record, 1998.

Nogueira, Érico. “Escrito nas Estrelas”. In: Bruno Tolentino, A balada do cárcere. $2^{a}$ edição. São Paulo: Record, no prelo.

. Verdade, contenda e poesia nos Idílios de Teócrito. São Paulo: Humanitas, 2012.

. O livro de Scardanelli. São Paulo: É Realizações, 2008.

Perez, Juliana Pasquarelli. “Breve Ensaio sobre 'As epifanias'em $A$ imitação do amanhecer, de Bruno Tolentino". Ipotesi.Juiz de Fora, v. 16, $\mathrm{n}^{\circ} 2$, pp. 129-140, julho/dezembro de 2012.

. "Os deuses de hoje: poesia e visões sobre o Brasil." Texto apresentado no Segundo Coloquio Latinoamericano de Literatura y Teología 'Identidad Latinoamericana y Cristianismo'. Santiago de Chile, 8 e 9 de outubro de 2008.

PessoA, Fernando. Obra poética. Rio de Janeiro: Nova Aguilar, 1969. . Obra em prosa. Rio de Janeiro: Nova Aguilar, 1974.

SECCHIN, Antonio Carlos. João Cabral: a poesia do menos. Rio de Janeiro: Topbooks, 1999.

Simas Rabello, Felipe. Ut Pictura Poesis: um panorama histórico das relações entre poesia e pintura. Tese de Doutoramento. Rio de Janeiro: Pontifícia Universidade Católica, 2014.

. O papel das sequências de sonetos em A imitação do amanhecer. Dissertação de Mestrado. Rio de Janeiro: Pontifícia Universidade Católica, 2010. 
SIMPSOn,Pablo. Rastro, hesitação e memória: o lugar do tempo na poesia de Yves Bonnefoy. Tese de Doutoramento. Campinas: Universidade de Campinas, 2006.

Siscar, Marcos. "A história como múmia: sobre a poesia de Bruno Tolentino". Revista Texto Poético, vol. 14, 1 semestre de 2013.

Tolentino, Bruno. A imitação do amanhecer. São Paulo: Globo, 2006. . O mundo como ideia. São Paulo: Globo, 2002. . Anulação \& outros reparos. Edição Definitiva. Rio de Janeiro: Topbooks, 1998. - A balada do cárcere. Rio de Janeiro: Topbooks, 1996. . "Quero meu País de Volta". Revista Veja, "Páginas Amarelas", edição $n^{\circ}$ 1436, 20 de março de 1996b. . Os deuses de hoje. São Paulo: Record, 1995. . Os sapos de ontem. Rio de Janeiro: Diadorim, 1995. . As horas de Katharina. São Paulo: Companhia das Letras, 1994. . About the Hunt. Oxford: OPN, 1978. . Le vrai Le vain: um lume no exílio. Paris: Actuels, 1971. . Anulação \& outros reparos. São Paulo: MassaoOhno, 1963. 


\section{Resumo}

Se uma tendência classicizante distingue a produção de vários dos mais representativos poetas brasileiros do último quarto de século, a poesia de Bruno Tolentino (1940-2007), pela repercussão que causou, talvez valha por emblema de toda a tendência. Desse modo, o que pretendemos, primeiro, é fazer sucinto apanhado da poética do autor, tal e como aparece no mais longo e importante ensaio crítico que escreveu, e, depois, mostrar brevemente como A balada do cárcere, cuja segunda edição se encontra no prelo, é uma possível expressão concreta dos mesmos princípios teóricos.

\section{Abstract}

If a classicizing trend is the hallmark of some of the best and most prestigious poetry produced in Brazil during the last 25 years, so Bruno Tolentino's work is worth considering as a symbol or quintessence of this whole trend. Therefore this paper is, first, a brief study of his most important essay on poetics and, second, an analysis of A Balada do Cárcere as a possible expression of his poetic principles. 